\title{
A comparison of ship and satellite measurements of cloud properties with global climate model simulations in the southeast Pacific stratus deck
}

\author{
M. A. Brunke ${ }^{1}$, S. P. de Szoeke ${ }^{2}$, P. Zuidema ${ }^{3}$, and X. Zeng ${ }^{1}$ \\ ${ }^{1}$ The University of Arizona, Department of Atmospheric Sciences, Tucson, Arizona, USA \\ ${ }^{2}$ Oregon State University, College of Oceanic and Atmospheric Sciences, Corvallis, Oregon, USA \\ ${ }^{3}$ University of Miami, Rosentiel School of Marine and Atmospheric Science, Miami, Florida, USA
}

Received: 20 October 2009 - Published in Atmos. Chem. Phys. Discuss.: 8 February 2010

Revised: 16 June 2010 - Accepted: 28 June 2010 - Published: 16 July 2010

\begin{abstract}
Here, liquid water path (LWP), cloud fraction, cloud top height, and cloud base height retrieved by a suite of A-train satellite instruments (the CPR aboard CloudSat, CALIOP aboard CALIPSO, and MODIS aboard Aqua) are compared to ship observations from research cruises made in 2001 and 2003-2007 into the stratus/stratocumulus deck over the southeast Pacific Ocean. It is found that CloudSat radar-only LWP is generally too high over this region and the CloudSat/CALIPSO cloud bases are too low. This results in a relationship (LWP $\sim h^{9}$ ) between CloudSat LWP and CALIPSO cloud thickness $(h)$ that is very different from the adiabatic relationship (LWP $\sim h^{2}$ ) from in situ observations. Such biases can be reduced if LWPs suspected to be contaminated by precipitation are eliminated, as determined by the maximum radar reflectivity $Z_{\max }>-15 \mathrm{dBZ}$ in the apparent lower half of the cloud, and if cloud bases are determined based upon the adiabatically-determined cloud thickness $\left(h \sim \mathrm{LWP}^{1 / 2}\right)$. Furthermore, comparing results from a global model (CAM3.1) to ship observations reveals that, while the simulated LWP is quite reasonable, the model cloud is too thick and too low, allowing the model to have LWPs that are almost independent of $h$. This model can also obtain a reasonable diurnal cycle in LWP and cloud fraction at a location roughly in the centre of this region $\left(20^{\circ} \mathrm{S}\right.$, $85^{\circ} \mathrm{W}$ ) but has an opposite diurnal cycle to those observed aboard ship at a location closer to the coast $\left(20^{\circ} \mathrm{S}, 75^{\circ} \mathrm{W}\right)$. The diurnal cycle at the latter location is slightly improved in the newest version of the model (CAM4). However, the simulated clouds remain too thick and too low, as cloud bases are usually at or near the surface.
\end{abstract}

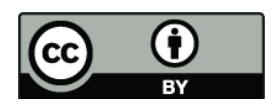

Correspondence to: $\mathrm{M}$. A. Brunke (brunke@atmo.arizona.edu)

\section{Introduction}

Clouds cover a large portion of the Earth while having a profound impact on the Earth's radiative balance and thus also on the climate system's sensitivity to climate forcing. There is a significant scatter in the climate sensitivity between global models that is largely due to uncertainties in cloud processes (Bony et al., 2006 and references therein).

Clouds have long been poorly simulated in models, and among the trickiest clouds to simulate are stratus $(\mathrm{St})$ and stratocumulus (Sc). These clouds cover $34 \%$ of the global ocean with some of the greatest amounts in large decks under the influence of subtropical descent over the eastern ocean basins (Klein and Hartmann, 1993). The presence of these clouds has a direct effect on the marine atmospheric boundary layer (MABL) from entrainment processes linked to the radiative and evaporative cooling at cloud top. These clouds also cool the sea surface which has a direct effect on ocean surface fluxes and thus the MABL as well. The sea surface temperature (SST) bias in the eastern Pacific was reduced by as much as $5 \mathrm{~K}$ in a global climate model when a prescribed stratus deck over the southeast Pacific was included (Ma et al., 1996).

The modeling of St/Sc would benefit from further knowledge of the complex interactions within these clouds. This can be facilitated through aircraft and ship observations of cloud properties such as liquid water path; cloud fraction; and cloud base, top, and thickness. Such measurements were made aboard ship over the southeast Pacific (SEP) in 2001 and 2003-2008 during the austral spring (OctoberDecember) when the $\mathrm{St} / \mathrm{Sc}$ fraction in this region is the highest (e.g., Bretherton et al., 2004; Kollias et al., 2004; Serpetzoglou et al., 2008; de Szoeke et al., 2009a). These quantities have also been derived from satellite measurements (e.g.,

Published by Copernicus Publications on behalf of the European Geosciences Union. 
Table 1. In situ data used in this study. See the text for the meaning of the experiment acronyms.

\begin{tabular}{|c|c|c|c|c|c|c|c|}
\hline \multirow[b]{2}{*}{ Experiment } & \multirow[b]{2}{*}{ Reference(s) } & \multirow[b]{2}{*}{ Year(s) } & \multirow[b]{2}{*}{ Location } & \multicolumn{4}{|c|}{ Instrumentation for acquiring } \\
\hline & & & & Liquid water path & Cloud fraction & Cloud base & Cloud top \\
\hline \multicolumn{8}{|l|}{ Ship/Surface } \\
\hline Stratus cruises & 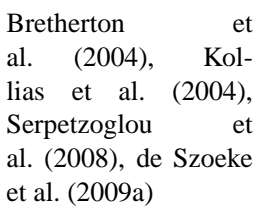 & 2001, 2003-2007 & SE Pacific & MWR & ceilometer & ceilometer & MMCR \\
\hline ASTEX & $\begin{array}{l}\text { Table } 2 \text { in White et } \\
\text { al. (1995) }\end{array}$ & 1992 & N Atlantic & MWR & ceilometer & ceilometer & 915-MHz radar \\
\hline TIWE & $\begin{array}{l}\text { Table } 2 \text { in White et } \\
\text { al. (1995) }\end{array}$ & 1991 & Eq. Central Pacific & MWR & ceilometer & ceilometer & 915-MHz radar \\
\hline \multicolumn{8}{|l|}{ Aircraft } \\
\hline RACE & $\begin{array}{l}\text { Table } 1 \text { in Räisänen et } \\
\text { al. (2003) }\end{array}$ & 1995 & Canada & FSSP & & & \\
\hline ASTEX & $\begin{array}{l}\text { Fig. } 1 \text { and } 2 \text { in Wood } \\
\text { and Field }(2000)\end{array}$ & 1992 & N Atlantic & Hot wire probe & & & \\
\hline FIRE & $\begin{array}{l}\text { Table } 2 \text { in Austin et } \\
\text { al. (1995) }\end{array}$ & 1987 & NE Pacific & FSSP, 260X & & & \\
\hline
\end{tabular}

$\mathrm{MWR}=$ microwave radiometer, $\mathrm{MMCR}=$ millimeter-wave cloud radar,

$\mathrm{FSSP}=$ forward scattering spectrometer probe, $260 \mathrm{X}=$ optical array probe

Zuidema and Hartmann, 1995) with some of the most recent retrievals from the CloudSat and Cloud-Aerosol Lidar and Infrared Pathfinder Satellite Observations (CALIPSO) satellites.

Here, we compare in situ observations of cloud properties of St/Sc over the southeast Pacific during cruises from 2001 to 2007 with those obtained from CloudSat, CALIPSO, and the Moderate Resolution Imaging Spectrometer (MODIS). The data are briefly explained in Sect. 2. The results of these comparisons as well as their application to evaluating a climate model are presented in Sect. 3. We finally summarize the results in Sect. 4.

\section{Data}

The experimental data are summarized in Table 1. Most of the in situ data are from a series of cruises undertaken by the U.S. National Oceanic and Atmospheric Administration (NOAA) R/V Ronald H. Brown into the SEP during the austral spring of 2001 and every spring from 2003-2008 (e.g., de Szoeke et al., 2009a). These are hereafter referred to as the Stratus cruises. These data are available at http: //www.esrl.noaa.gov/psd/psd3/synthesis/ and documented in de Szoeke et al. (2010). The cloud properties of interest here are liquid water path (LWP), physically-derived following Zuidema et al. (2005) and averaged to minimize occasional uncertain calibration; the mean cloud fraction; the median cloud base height; and the mean cloud top height for 10-min periods. The instruments used to obtain these quantities in these field experiments are summarized in Table 1.

The statistical relationships between several quantities in the pre-2008 Stratus cruise data are compared to those reported from surface and aircraft data during the Atlantic Stratocumulus Transition Experiment (ASTEX); the First International Satellite Cloud Climatology Program Regional Experiment (FIRE); the Radiation, Aerosol, and Cloud Experiment (RACE); and the Tropical Instability Wave Experiment (TIWE) as documented in the references listed in Table 1. The instruments used to obtain the cloud properties of interest here for these experiments are also listed in Table 1.

Since 2006, data from the Cloud Profiling Radar (CPR) have been available. The CPR is a nadir-viewing space-based 94-GHz radar that is the sole instrument on board CloudSat (Stephens et al., 2008). As part of the A-Train, CloudSat closely follows the Aqua satellite which houses MODIS and the Advanced Microwave Scanning Radiometer-EOS (AMSR-E) and is closely followed by CALIPSO which houses the Cloud-Aerosol Lidar with Orthogonal Polarization (CALIOP) - a nadir-pointing Nd:YAG lidar that operates at 532 and $1064 \mathrm{~nm}$ (Winker et al., 2007). The CloudSat Data Processing Centre (http://www.cloudsat.cira.colostate. edu) produces collocated CPR, CALIOP, and MODIS Level 2B data products. Specifically used here are the $2 \mathrm{~B}-\mathrm{CWC}$ $\mathrm{RO}$ for CPR-derived liquid water path, 2B-GEOPROF for MODIS-derived cloud fraction which is only available for daytime passes, and 2B-GEOPROF-LIDAR for combined CALIOP- and CPR-derived cloud top and base from the second epoch of Release 4 for October-December from 
Table 2. Percentage of good-quality CloudSat LWP profiles removed, the mean differences in the LWPs between CloudSat and AMSR-E or SSM/I [mean( $\triangle \mathrm{LWP})]$, and the standard deviation in the differences between CloudSat and AMSR-E or SSM/I $[\sigma(\Delta \mathrm{LWP})]$ for various precipitation removal criteria in October-December 2008 for the region bounded by $12^{\circ} \mathrm{S}, 25^{\circ} \mathrm{S}, 70^{\circ} \mathrm{W}$, and $90^{\circ} \mathrm{W}$.

\begin{tabular}{|c|c|c|c|c|c|c|}
\hline \multirow[t]{2}{*}{ Reflectivity threshold (dBZ) } & \multirow[t]{2}{*}{ Maximum height of threshold } & \multirow[t]{2}{*}{ Percent removed } & \multicolumn{2}{|c|}{ mean $(\Delta \mathrm{LWP})\left(\mathrm{g} \mathrm{m}^{-2}\right)$} & \multicolumn{2}{|c|}{$\sigma(\Delta \mathrm{LWP})\left(\mathrm{g} \mathrm{m}^{-2}\right)$} \\
\hline & & & AMSR-E & $\mathrm{SSM} / \mathrm{I}$ & AMSR-E & $\mathrm{SSM} / \mathrm{I}$ \\
\hline None & & $0 \%$ & 82.3 & 91.9 & 170.1 & 191.5 \\
\hline$Z_{S} \geq-15$ & & $4 \%$ & 74.5 & 82.5 & 160.8 & 183.1 \\
\hline$Z_{\max }>-15$ & mid-cloud & $19 \%$ & -12.6 & -6.2 & 73.1 & 94.4 \\
\hline$Z_{\max }>-15$ & cloud top & $26 \%$ & -40.0 & -35.3 & 54.5 & 73.9 \\
\hline$Z_{\max }>-15$ & $4000 \mathrm{~m}$ & $25 \%$ & -39.7 & -35.4 & 55.6 & 73.4 \\
\hline$Z_{\max }>-16$ & mid-cloud & $20 \%$ & -15.1 & -9.1 & 72.2 & 93.2 \\
\hline$Z_{\max }>-16$ & cloud top & $28 \%$ & -44.9 & -41.4 & 53.1 & 71.6 \\
\hline$Z_{\max }>-17$ & mid-cloud & $21 \%$ & -17.5 & -11.6 & 71.6 & 92.5 \\
\hline$Z_{\max }>-17$ & cloud top & $30 \%$ & -49.5 & -47.3 & 51.7 & 69.4 \\
\hline$Z_{\max }>-18$ & mid-cloud & $22 \%$ & -19.5 & -14.0 & 71.5 & 91.7 \\
\hline$Z_{\max }>-18$ & cloud top & $32 \%$ & -53.6 & -51.9 & 50.3 & 68.0 \\
\hline$Z_{\max }>-18$ & $4000 \mathrm{~m}$ & $31 \%$ & -51.7 & -50.6 & 51.5 & 68.4 \\
\hline
\end{tabular}

$Z_{S}=$ near-surface reflectivity, $Z_{\max }=$ maximum reflectivity.

2006-2008 over the ocean only. While we anticipate that the $2 \mathrm{~B}-\mathrm{CWC}-\mathrm{RO}$ product would be highly influenced because of radar reflectivity's increased sensitivity to droplet size (as described in more detail in the following sections), the single-measurement retrieval is more homogenous than that from another product, the 2B-CWC-RVOD. The latter combines LWP based on the CPR and on MODIS-derived visible cloud optical depths which are unavailable in many situations, most notably at night. Thus, such a product is not favored here. To insure that good-quality retrievals of 2B-CWC-RO LWP are used, data that has a zero data quality flag are only used. LWPs with a fractional uncertainty $\geq 50 \%$ and that have been flagged as having used bad input data have also been discarded. Additionally, LWPs are only considered when a cloud is also detected in the 2B-GEOPROF-LIDAR product and for cloud tops $\geq 1000 \mathrm{~m}$ to eliminate the possibility of missed drizzle in shallow, low clouds (Leon et al., 2008).

CloudSat LWP from 2B-CWC-RO is further intercompared to passive microwave satellite products retrieved from the AMSR-E on Aqua and the Special Sensor Microwave Imager (SSM/I) aboard the Defense Meteorological Satellite Programme (DMSP) satellites during October-December 2006-2008. The latter data is from the version 6 ocean algorithm from Remote Sensing Systems (http://www.remss. com) (Wentz, 1997) for the F13 and F15 satellites. The AMSR-E data is derived from version 2 of the level 2B global swath ocean products (available at http://nsidc.org/ daac/index.html) which have been interpolated to the same $0.25^{\circ} \times 0.25^{\circ}$ regular grid as SSM/I.

\section{Results}

\subsection{Satellite intercomparison of LWP}

First, a direct comparison of the CloudSat retrievals and those from AMSR-E and SSM/I is facilitated by averaging all good-quality CloudSat LWPs that fall within an AMSR$\mathrm{E}$ or SSM $/ \mathrm{I} 0.25^{\circ} \times 0.25^{\circ}$ grid box for each individual pass. CloudSat LWP in October-December 2008 is on average higher than that of AMSR-E and SSM/I as indicated by the top line in Table 2. SSM/I generally has the lowest LWPs and its mean difference with CloudSat is $92 \mathrm{~g} \mathrm{~m}^{-2}$ with a standard deviation of $191 \mathrm{~g} \mathrm{~m}^{-2}$ for non-zero values in the core of the $\mathrm{St} / \mathrm{Sc}$ deck (between $12^{\circ}$ and $25^{\circ} \mathrm{S}$ and $70^{\circ}$ and $90^{\circ} \mathrm{W}$ ). The mean difference between non-zero CloudSat and AMSR-E values is less at $82 \mathrm{~g} \mathrm{~m}^{-2}$ with a standard deviation of $170 \mathrm{~g} \mathrm{~m}^{-2}$. Most of the high standard deviations of the difference are due to the variability in the CloudSat measurements which have a standard deviation of non-zero values of $187 \mathrm{~g} \mathrm{~m}^{-2}$, whereas those from AMSR-E and SSM/I are $67 \mathrm{~g} \mathrm{~m}^{-2}$ and $65 \mathrm{~g} \mathrm{~m}^{-2}$, respectively. Figure 1a shows that CloudSat overestimates a large number of grid boxes compared to AMSR-E and SSM/I. For CloudSat LWP $\geq 200 \mathrm{~g} \mathrm{~m}^{-2}$ in both the day and night passes combined, median AMSR-E LWPs increase slightly, while SSM/I's are generally constant. On the other hand, LWPs $<100 \mathrm{~g} \mathrm{~m}^{-2}$ are underestimated by CloudSat compared to AMSR-E and SSM/I. The large differences between CloudSat LWPs and those from the other products are due to the fact that, while all satellites have the most LWPs in the lowest bin $\left(<100 \mathrm{~g} \mathrm{~m}^{-2}\right)$, only CloudSat produces LWPs $\geq 500 \mathrm{~g} \mathrm{~m}^{-2}$ (Fig. 1b). 
As mentioned in the previous section, some of the above LWP derivations are contaminated by the presence of precipitation ( $\mathrm{Li}$ et al., 2008). In particular, radar reflectivity is highly sensitive to drop size $\left(\sim D^{6}\right.$ where $D$ is drop diameter) (Comstock et al., 2004), thus making radar-derived LWP highly sensitive to the larger precipitation drops. The passive microwave retrievals are also somewhat sensitive to precipitation, but any such error would be within instrument uncertainty (Zuidema et al., 2005).

To reduce the effect of precipitation on the radar-derived LWP retrievals, those LWPs that likely include precipitation (whether it is in- or below-cloud) can be excluded. The CloudSat team preliminarily flags possible precipitation for profiles where the unattenuated near-surface reflectivity $Z_{s} \geq-15 \mathrm{dBZ}$ (Haynes et al., 2009). Only $4 \%$ of the 536054 total good-quality profiles are removed in OctoberDecember 2008 with this flag, while there is little change to the mean differences between non-zero CloudSat LWPs and those from AMSR-E and SSM/I (Table 2).

Similarly, profiles can be excluded based upon a maximum reflectivity $\left(Z_{\max }\right)$ threshold. Matrosov et al. (2004) explored a variety of thresholds - from $-15 \mathrm{dBZ}$ to $-21 \mathrm{dBZ}$ - starting at various locations in the cloud using radar data from the EPIC cruise. They found that biases relative to microwave radiometer retrievals decreased with decreasing $Z_{\max }$ and as the maximum height to look for $Z_{\max }$ decreases. Table 2 shows that, as $Z_{\max }$ decreases and as the maximum height to look for $Z_{\max }$ increases in the CloudSat data, mean differences relative to AMSR-E and SSM/I decrease, the standard deviations of these differences decrease, and the number of profiles rejected increases.

Here, we only explore thresholds down to $-18 \mathrm{dBZ}$ which was used by Leon et al. (2008) in the lowest $4000 \mathrm{~m}$. They chose this because of its location near the minimum between two maxima in the PDF of $Z_{\max }$ due to drizzling and nondrizzling clouds. They found a precipitation occurrence of $34 \%$ for profiles with cloud top between 1000 and $4000 \mathrm{~m}$ in this region. The use of the same threshold on the CloudSat data used here would eliminate $31 \%$ of all good-quality profiles and all LWPs $\geq 500 \mathrm{~g} \mathrm{~m}^{-2}$, while only a handful remain for LWPs between 200 and $500 \mathrm{~g} \mathrm{~m}^{-2}$ (Fig. 1b). However, AMSR-E and SSM/I still have a little less than $10 \%$ of their LWPs between 200 and $300 \mathrm{~g} \mathrm{~m}^{-2}$. As expected from the above discussion, the mean difference between nonzero CloudSat and AMSR-E (SSM/I) LWPs have been reduced to large negative values $\left[-52(-51) \mathrm{g} \mathrm{m}^{-2}\right]$ with a corresponding decrease in the standard deviation of the differences $\left[51(68) \mathrm{g} \mathrm{m}^{-2}\right]$. Note that the amount rejected is lower, the mean differences are slightly better, and the standard deviation of the differences are slightly higher for the 4000-m maximum heights than for the cloud top maximum heights for both $Z_{\max }>-15$ and $-18 \mathrm{dBZ}$ here. A few of the profiles have cloud tops above $4000 \mathrm{~m}$ that are still included here, whereas they were excluded from Leon et al. (2008).
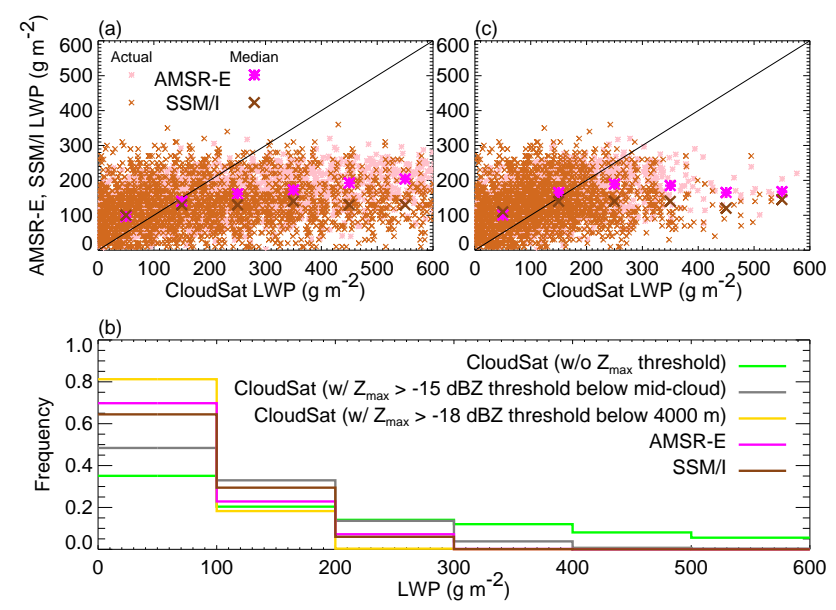

Fig. 1. (a) Non-zero liquid water paths (LWPs) from AMSR$\mathrm{E}$ and SSM/I compared to those from CloudSat averaged over $0.25^{\circ} \times 0.25^{\circ}$ grid boxes within $12^{\circ}-25^{\circ} \mathrm{S}$ and $70^{\circ}-90^{\circ} \mathrm{W}$ in October-December 2006-2008. (b) The frequency distribution of LWP per $100 \mathrm{~g} \mathrm{~m}^{-2}$ bin for all good-quality CloudSat profiles, CloudSat profiles with suspected precipitation contamination removed based upon a maximum reflectivity $Z_{\max }>-15 \mathrm{dBZ}$ below the apparent middle of the cloud and $Z_{\max }>-18 \mathrm{dBZ}$ below $4000 \mathrm{~m}$ similar to Leon et al. (2008), AMSR-E, and SSM/I. (c) Same as in (a) except for CloudSat profiles with suspected precipitation contamination removed based upon a maximum reflectivity $Z_{\max }>-15 \mathrm{dBZ}$ below the apparent middle of the cloud.

The lowest in magnitude mean differences occur for $Z_{\max }>-15 \mathrm{dBZ}$ below mid-cloud where Wang and Geerts (2003) found that such a threshold was most accurately defined. The non-zero CloudSat LWPs that pass this threshold are compared to those from AMSR-E and SSM/I in Fig. 1c. There are still some overestimates from CloudSat for $L W P \geq 200 \mathrm{~g} \mathrm{~m}^{-2}$, so the median AMSR-E and SSM/I LWPs for these bins do not change much. Even so, the frequency of occurrences $\geq 300 \mathrm{~g} \mathrm{~m}^{-2}$ is practically zero, while there is still $\sim 10 \%$ of the $0.25^{\circ} \times 0.25^{\circ}$ averages remaining for $200 \leq \mathrm{LWP}<300 \mathrm{~g} \mathrm{~m}^{-2}$ (Fig. 1c).

\subsection{Satellite comparison of cloud properties with ship observations}

The relationship between LWP and cloud thickness $(h)$ from CloudSat/CALIPSO is compared to that from the Stratus cruises in Fig. 2a. Some studies showed that liquid water content (LWC) is adiabatic or near-adiabatic within $\mathrm{St} / \mathrm{Sc}$ (e.g., Albrecht et al., 1990; Zuidema et al., 2005), while others found that LWC can deviate substantially from adiabaticity (e.g., Pawlowska et al., 2000; Zhou et al., 2006). In either case, LWP is directly related to $h$, as LWP is the integral of LWC over the cloud depth (Zhou et al., 2006):

$\mathrm{LWP}=\alpha \frac{A}{2} h^{2}$ 

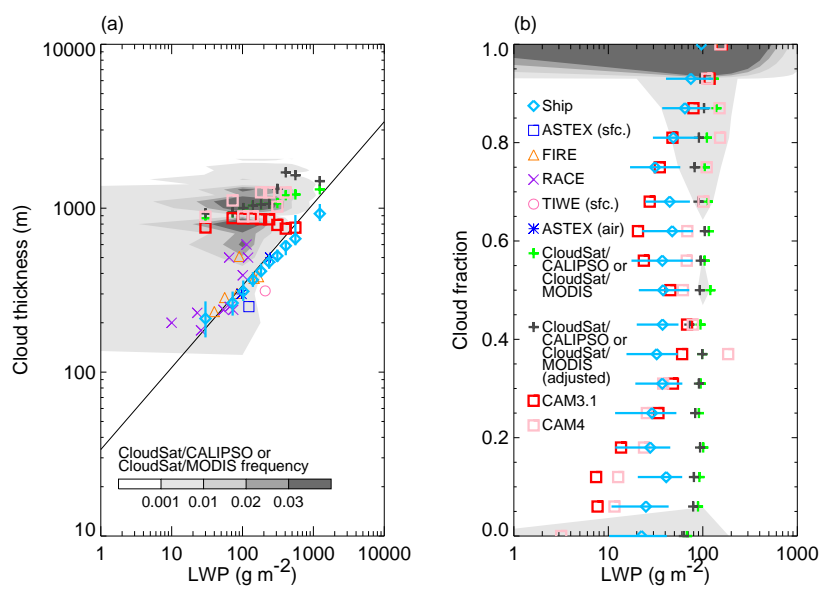

Fig. 2. (a) Median cloud thickness for LWP bins of varying size from the 2001-2007 Stratus cruises (with the interquartile ranges indicated by the vertical lines), CloudSat/CALIPSO (with and without precipitation removed), CAM3.1, and CAM4 along with values derived from various other field experiments [ASTEX (surface and aircraft), FIRE, RACE, and TIWE]. Also shown is the frequency distribution of CloudSat LWP/CALIPSO thickness data pairs. The thin line is the fit to Eq. (1). (b) Median LWP for cloud fraction bins of varying size from the Stratus cruises (with the interquartile ranges indicated by the horizontal lines), CloudSat/MODIS (with and without precipitation removed), CAM3.1, and CAM4.

where $A$ is the adiabatic rate of change with height of LWC and $\alpha$ is the percentage of adiabaticity. Zhou et al. (2006) found a median value for $A$ of $2.24 \times 10^{-3} \mathrm{~g} \mathrm{~m}^{-4}$ and a value for $\alpha$ of 0.79 . This relationship is shown as the solid line in Fig. 2a, and the Stratus cruise data almost fall onto this line. This is not surprising, as some of the Stratus 2001 data along with the other data from TIWE, FIRE, RACE, and ASTEX were used to derive that relationship. The original CloudSat/CALIPSO data, however, have a very different relationship of LWP $\sim h^{9}$. This relationship is largely undisturbed even when suspected precipitation contamination is removed with the $Z_{\max }>-15 \mathrm{dBZ}$ threshold below mid-cloud. In fact, the clouds tend to be even thicker for large LWPs.

In Fig. 2b, the relationship between Stratus cruise LWP and cloud fraction is compared to that from CloudSat/MODIS. The ship observations show a somewhat logarithmic increase in median LWP with increasing cloud fraction as in Zhou et al. (2006). However, MODIS cloud fraction is nearly independent of the median CloudSat LWP even when possible precipitation contamination is removed.

The large differences between the relationships from the CloudSat team's products and those observed are probably due to the retrieved cloud thickness and cloud fraction, especially when the LWPs likely affected by precipitation are removed. Figure 3 compares the median cloud properties from satellite retrievals for $\sim 2.8^{\circ}$ latitude and longitude bands in October-December 2006-2008 with those observed aboard the pre-2008 Stratus cruises. Without eliminating suspected precipitation contamination, the medians of all good-quality non-zero CloudSat LWP are generally higher than non-zero ship LWPs in the core region of the St/Sc deck (Fig. 3a, e). Again, this is to be expected due to the radar's sensitivity to precipitation, while the retrievals from the passive microwave radiometer aboard the ship would be less sensitive. In comparison, the AMSR-E and SSM/I retrievals which are also less sensitive to precipitation are generally within the ship IQRs except for SSM/I at $\sim 24^{\circ} \mathrm{S}, \sim 85^{\circ} \mathrm{W}, \sim 76^{\circ} \mathrm{W}$, and $\sim 73^{\circ} \mathrm{W}$. With the exclusion of suspected precipitation contamination, the CloudSat LWPs do not vary much across all latitudes and longitudes and is generally within the ship IQRs except for at $\sim 24^{\circ} \mathrm{S}$ and close to the coast where the precipitation-free LWP approaches the original LWP.

Median cloud fraction from the ship ceilometer is generally 1 but is reduced at $\sim 24^{\circ} \mathrm{S}, \sim 90^{\circ} \mathrm{W}$, and $\sim 70^{\circ} \mathrm{W}$. MODIS cloud fraction is almost always 1 except at $\sim 70^{\circ} \mathrm{W}$. In Fig. 2b, it can be seen that a very large fraction of MODIS points are nearly completely overcast, whereas the ship observes more of the lower cloud fractions as well (not shown). This may account for the lack of relationship between MODIS cloud fraction and CloudSat LWP seen here.

The CloudSat/CALIPSO cloud base is generally lower than observed from the ship (Fig. 3c, g), whereas cloud top agrees well with the ship observations (Fig. 3d, h). This suggests that the CloudSat/CALIPSO-derived clouds are too thick in this region. According to Winker and Vaughan (1994), lidar signals are highly attenuated in stratus-type clouds and may not be able to make it through such clouds. Also, the presence of precipitation may also make the determination of cloud base from lidar tenuous. When the lidar is not able to detect cloud base, it is determined from the radar which is affected by the presence of drizzle just like the LWPs are. This occurs in only $26 \%$ of the total number of profiles.in this region, so the lower cloud base is unlikely to be just due to the influence of the radar-determined cloud bases. Also shown in Fig. 3c, g are CloudSat/CALIPSO cloud bases calculated by subtracting the adiabatic cloud thickness in Eq. (1) using the precipitation-free LWPs from the product cloud tops. Like the LWPs without suspected precipitation contamination, these cloud bases do not vary much across all latitudes and longitudes at $\sim 1250 \mathrm{~m}$. These bases fall within the ship IQRs for all latitudes but only do in the longitude bands west of $\sim 82.5^{\circ} \mathrm{W}$. So unlike in the ship observations, the adiabatic cloud bases do not drop with the cloud tops into the centre of the region, and the clouds there would be much thinner than they are in the western part of the region. The adiabatic cloud bases are ignored east of $\sim 79^{\circ} \mathrm{W}$, because there are not enough retrievals here based on the precipitation-free LWPs to adequately compare with the original CloudSat/CALIPSO cloud bases and tops.

The diurnal cycle of these cloud properties are compared in Fig. $4 \mathrm{a}-\mathrm{d}$ within $1^{\circ}$ of $\left(20^{\circ} \mathrm{S}, 85^{\circ} \mathrm{W}\right)$, i.e., the nominal location of the buoy operated by the Woods Hole 

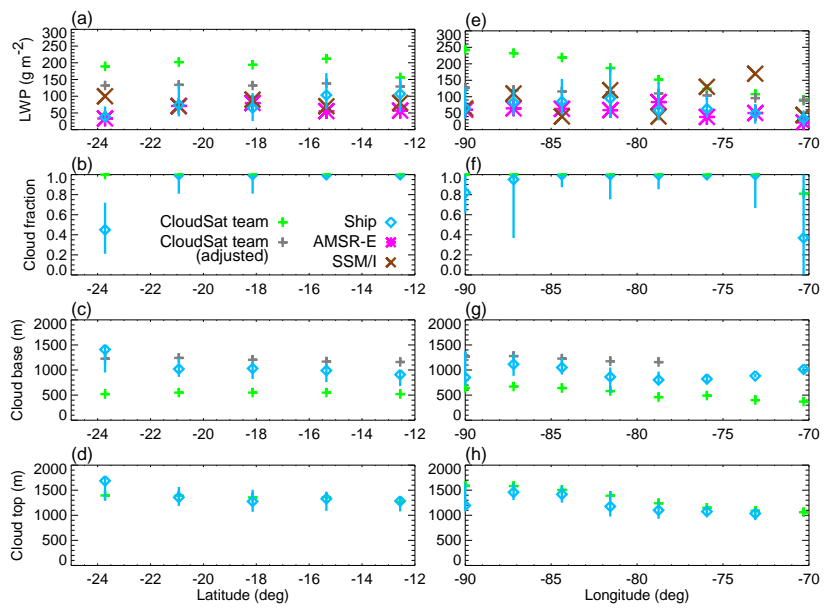

Fig. 3. Median (a, d) LWP, (b, f) cloud fraction, (c,g) cloud base height, and $(\mathrm{d}, \mathrm{h})$ cloud top height for $\sim 2.8^{\circ}$ latitude $(\mathrm{a}-\mathrm{d})$ and longitude (e-h) bands from the 2001-2007 Stratus cruises (with the interquartile ranges indicated by the vertical lines); the CloudSat team products with LWPs adjusted to remove suspected precipitation contamination and based upon adiabatic cloud bases derived from thicknesses from Eq. (1) also shown; and AMSR-E and SSM/I for LWP only.

Oceanographic Institution. The ship-observed hourly median of 10-min non-zero LWP has a maximum of $154 \mathrm{~g} \mathrm{~m}^{-2}$ in the early morning (at 05:00 LT) and a minimum of $35 \mathrm{~g} \mathrm{~m}^{-2}$ in the afternoon (at 13:00 LT) (Fig. 4a) quite similar to the diurnal cycle obtained from all ship observations during Stratus 2001 only (Zuidema et al., 2005, Fig. 10). The median cloud fraction is less than 1 only between 12:00 and 16:00 LT with values as low as 0.95 (Fig. 4b). Ship cloud base and top change little throughout the day with a difference of only $150 \mathrm{~m}$ and $126 \mathrm{~m}$, respectively, between their maxima and minima (Fig. 4c, d).

Because of the sun-synchronous orbits of their satellites, CloudSat and CALIPSO values can only be obtained at this site twice during the mean diurnal cycle, and MODIS values are only available once per day during daytime. Preexclusion non-zero CloudSat LWP is lower in the day than at night which is consistent with the ship observations. As expected from the increased sensitivity of the radar to precipitation, the satellite-derived LWP values are higher than the ship data (by $157 \mathrm{~g} \mathrm{~m}^{-2}$ at night and $104 \mathrm{~g} \mathrm{~m}^{-2}$ in the day, Fig. 4a). On the other hand, AMSR-E and SSM/I LWPs are within the ship IQRs at all times. The exclusion of probable precipitating profiles greatly helps the morning LWP which is pulled down into the ship IQRs, while the afternoon LWP is only slightly reduced. As before, CloudSat/CALIPSO cloud base is lower than the ship observations (by $502 \mathrm{~m}$ at night and $156 \mathrm{~m}$ in the daytime) with a slightly higher diurnal cycle than the ship with a difference between the daytime and nighttime passes of $210 \mathrm{~m}$ (Fig. 4c). The adiabatic cloud bases are now slightly higher than the ship observations and
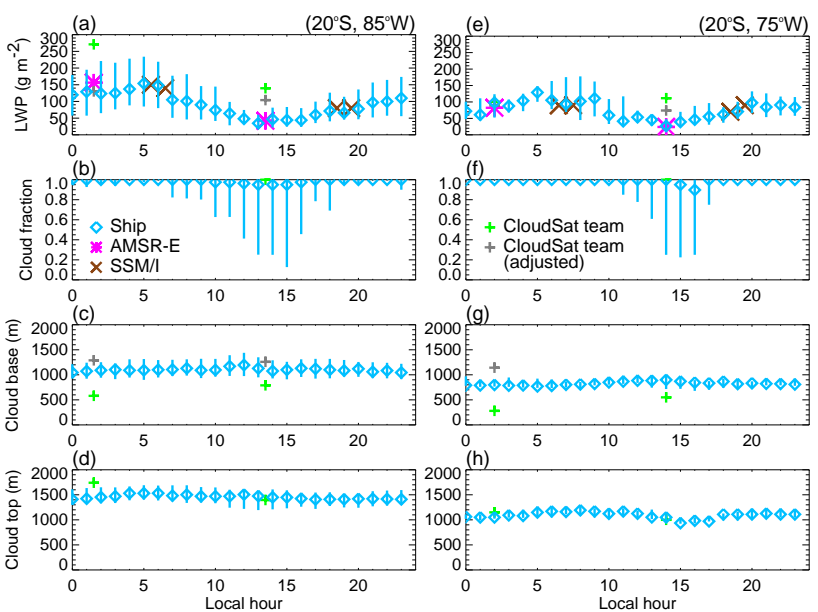

Fig. 4. Median hourly (a, e) LWP, (b, f) cloud fraction, (c, g) cloud base, and $(\mathrm{d}, \mathrm{h})$ cloud top at $\left(20^{\circ} \mathrm{N}, 85^{\circ} \mathrm{W}\right)(\mathrm{a}-\mathrm{d})$ and at $\left(20^{\circ} \mathrm{N}, 75^{\circ} \mathrm{W}\right)(\mathrm{e}-\mathrm{h})$ from the 2001-2007 Stratus cruises (with the interquartile ranges indicated by the vertical lines); and the CloudSat team products with LWPs adjusted to remove suspected precipitation contamination and based upon adiabatic cloud bases derived from thicknesses from Eq. (1) also shown; and AMSR-E and SSM/I for LWP only.

are improved at night (207 $\mathrm{m}$ higher). In contrast, CALIPSO cloud top is closer to the ship-observed values ( $302 \mathrm{~m}$ higher at night and $66 \mathrm{~m}$ lower in the day) but has a higher difference between passes ( $345 \mathrm{~m}$, Fig. $4 \mathrm{~d}$ ) possibly due to the higher variability in the CloudSat team data (not shown).

The satellite cloud properties are further compared with the ship observations at $\left(20^{\circ} \mathrm{S}, 75^{\circ} \mathrm{W}\right)$, a location closer to the coast near the Chilean Servicio Hidrográfico y Oceanográfico de la Armada (SHOA) buoy (Fig. 4e-h). Here, the ship observations within $1^{\circ}$ of this location show a somewhat similar diurnal cycle to that at the western location with a maximum LWP at 05:00 LT and a minimum LWP at 14:00 LT (Fig. 4e). The ship observations here also exhibit a secondary maximum in the evening (at 20:00 LT) which is consistent with previous findings from satellite retrievals in the region (O'Dell et al., 2008). This is about the time that modeled upward motion associated with the upsidence wave reaches this point (Rahn and Garreaud, 2010). There are more hours with complete cloud cover at this location with only two hours (15:00-16:00 LT) of median cloud fraction $<1$ (Fig. 4f). Again, cloud base does not change very much over the course of the day (Fig. 4g), but cloud top has a little more variability with a difference of $257 \mathrm{~m}$ between the minimum in the afternoon (15:00 LT) and the maximum in the morning (8:00 LT) (Fig. 4h).

Pre-exclusion CloudSat measurements of LWP within $1^{\circ}$ of $\left(20^{\circ} \mathrm{S}, 75^{\circ} \mathrm{W}\right)$ are closer to the ship observations here (Fig. 4e) than at $85^{\circ} \mathrm{W}$. Again, AMSR-E and SSM/I LWPs all fall within the ship IQRs, and the removal of suspected 
precipitation contamination helps the afternoon LWP from CloudSat. As at $85^{\circ} \mathrm{W}$, CALIPSO cloud top compares well with the ship (Fig. 4h), but again CALIPSO cloud base is too low, particularly at night (Fig. 4g). The adiabatic cloud base at night is improved, while the daytime adiabatic cloud base is ignored due to the low number of profiles available to compare with the original cloud bases and tops.

\subsection{Model evaluation of cloud properties}

A further motivation of using these ship and satellite measurements is to use them to evaluate model simulated cloud properties. Here, we are using the Community Atmosphere Model (CAM) which is a component of the fully-coupled Community Climate System Model (CCSM). Both version 3.1 and the recently-released version 4 were run from October 1991 to December 2008 coupled solely with the Community Land Model (CLM) at T42 spectral truncation ( $2.8^{\circ}$ latitude $\times \sim 2.8^{\circ}$ longitude) using observed sea surface temperatures and ice cover from the Reynolds et al. (2002) product. Branch runs were initiated for three months beginning on October 1 of 2006, 2007, 2008 to output every hour instead of monthly.

The relationship between LWP and $h$ in the hourly output from both versions is also shown in Fig. 2a. LWP in CAM3.1 is almost independent of $h$. On the other hand, the relationship between LWP and cloud fraction is fairly logarithmic in CAM3.1 similar to the ship observations (Fig. 2b). CAM4 retains a similar logarithmic relationship between LWP and cloud fraction and a lack of relationship between LWP and cloud thickness.

The median hourly output is compared to ship and CloudSat team measurements in Fig. 5 over $\sim 2.8^{\circ}$ latitude and longitude bands as in Fig. 3. Note that only the precipitationremoved LWP and adiabatic cloud bases are shown now. CAM3.1 LWPs are generally within the ship IQRs, and so are CAM4 LWPs except at $\sim 24^{\circ} \mathrm{S}$ where its value is quite similar to CloudSat's overestimate (Fig. 5a, e). CAM3.1 total cloud fractions are generally lower than both the ship and MODIS but are still generally within the ship IQRs (Fig. 5b, f). On the other hand, CAM4 decreases the simulated cloud fraction further north of $\sim 24^{\circ} \mathrm{S}$ and east of $\sim 87^{\circ} \mathrm{W}$, making the values less than the ship IQRs.

Simulated cloud base and top are not standard output for CAM. As the model does not determine what vertical fraction of the model box the cloud spans, one could say that the simulated cloud spans the whole model layer. Thus, we define model cloud base as the bottom of the lowest layer with non-zero cloud fraction, and cloud top as the bottom of the layer where cloud fraction returns to zero above cloud base. Cloud base in both versions is generally quite low, at or near the surface, whereas the ship and CloudSat/CALIPSO measurements are much higher (Fig. 5c, g). CAM4 does improve the bases north of $\sim 18^{\circ} \mathrm{S}$ but degrades the bases west of $\sim 84^{\circ} \mathrm{W}$. Cloud tops in CAM3.1 are generally lower
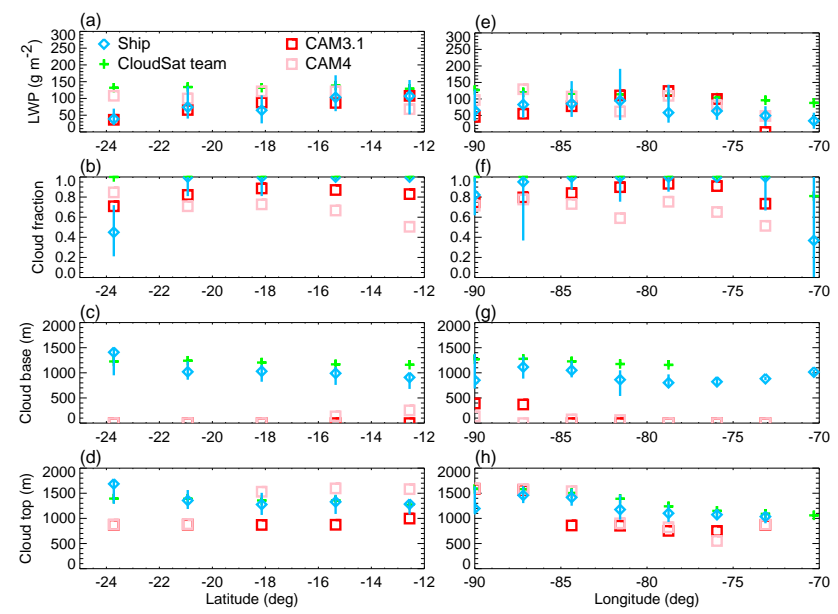

Fig. 5. Same as Fig. 3 showing data only from the 2001-2007 Stratus cruises (light blue diamonds, with the interquartile ranges indicated by the vertical lines) and the CloudSat team products including LWPs with suspected precipitation contamination removed and adiabatic cloud bases based on thicknesses from Eq. (1) only with simulated quantities from CAM3.1 and CAM4.
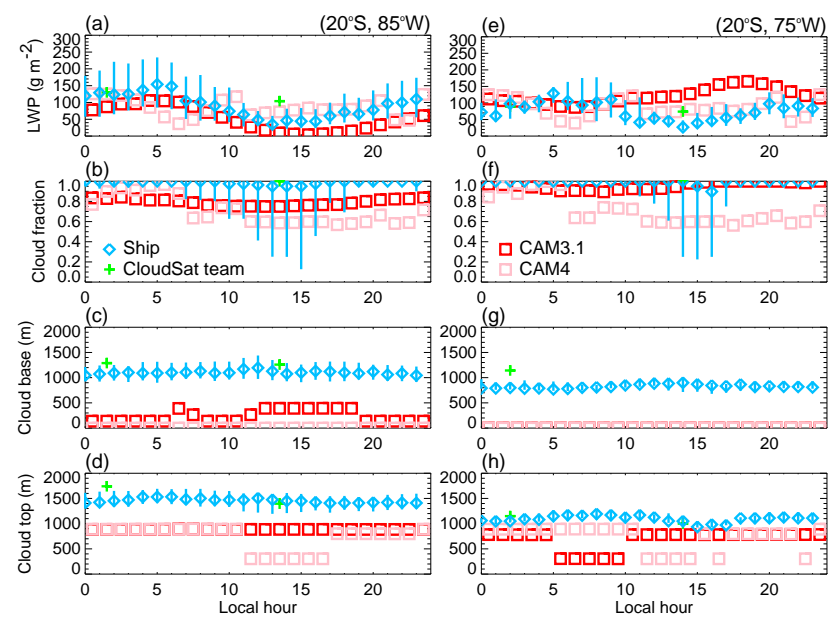

Fig. 6. Same as Fig. 4 showing only data from the 2001-2007 Stratus cruises (light blue diamonds, with the interquartile ranges indicated by the vertical lines) and the CloudSat team products including LWPs with suspected precipitation contamination removed and adiabatic cloud bases based on thicknesses from Eq. (1) only with simulated quantities from CAM3.1 and CAM4.

than the ship and CloudSat/CALIPSO values except west of $\sim 84^{\circ} \mathrm{W}$ (Fig. $5 \mathrm{~d}, \mathrm{~h}$ ). CAM 4 does improve the tops to slightly above ship IQRs north of $\sim 21^{\circ} \mathrm{S}$ and to within the ship IQR at $\sim 84^{\circ} \mathrm{W}$. While part of these differences in the model is due to how cloud base and top had to be defined here, this still suggests that the simulated clouds in the model are too thick and too low which could be improved if the number of layers was increased from the current 26 especially near the surface. 
The model diurnal cycle is compared to ship observations and the CloudSat team products in Fig. 6. CAM3.1 is able to correctly capture the observed diurnal cycle in LWP and cloud fraction at $\left(20^{\circ} \mathrm{S}, 85^{\circ} \mathrm{W}\right)$ with a minimum in the afternoon (albeit delayed by $\sim 3$ hours) and a maximum in the early morning (Fig. 6a,b). Cloud base is also a maximum in the afternoon and early evening at this location somewhat consistent with the ship observations which have its maximum at 12:00 LT (Fig. 6c). However, there is a secondary maximum in CAM3.1 at 06:30 LT which does not appear in the ship observations (Fig. 6c), and the CAM3.1 cloud tops are constant with time (Fig. 6d).

CAM3.1 produces a very different diurnal cycle in LWP than what is observed aboard ship at $\left(20^{\circ} \mathrm{S}, 75^{\circ} \mathrm{W}\right)$ with a maximum in the early evening at 18:30 LT and a minimum in the morning at 06:30 LT (Fig. 6e). Cloud fraction is also lower in the morning opposite that of the ship observations in the afternoon (Fig. 6f). Cloud base is constantly at the surface (Fig. 6g), but, like LWP and cloud fraction, CAM3.1 cloud top is lower in the morning (Fig. 6h). Otherwise, model cloud top is closer to the ship observations than cloud base (Fig. 6g,h).

CAM4 is able to produce a somewhat better diurnal cycle at $\left(20^{\circ} \mathrm{S}, 75^{\circ} \mathrm{W}\right)$ with LWPs more consistent with the ship and CloudSat values in the afternoon and a secondary maximum at 20:30 LT. However, the absolute minimum is in the morning at 06:30 LT and the absolute maximum is at 10:30 LT (Fig. 6a), whereas they are at 14:00 LT and 05:00 LT, respectively, in the ship observations. CAM4 is also able to produce lower values of cloud fraction and cloud top in the afternoon and evening rather than in the morning at this location (Fig. 6f, h), but cloud base is still constantly at the surface (Fig. 6g).

CAM4's diurnal cycle at $\left(20^{\circ} \mathrm{S}, 85^{\circ} \mathrm{W}\right)$ is now very similar to that at $75^{\circ} \mathrm{W}$ (Fig. 6a-d). This helps the LWP values from late morning into the early evening. However, the simulated minimum at 06:30 LT and the secondary maximum at 20:30 LT is quite different than the ship observations. Also, the diurnal cycle in cloud top is improved with the lowest values happening in the afternoon even though the values are still too low (Fig. 6d). However, cloud base is lowered to the surface at all times, while they were above the surface at all times in CAM3.1 (Fig. 6c).

\section{Conclusions}

Some differences in the collocated CloudSat, CALIPSO, and MODIS measurements of cloud properties have been found here in the SEP St/Sc deck when compared to those from other satellite products and ship observations. For instance, the clouds as measured by CloudSat and CALIPSO are on average too thick, because the cloud bases are too low compared to ship observations (Figs. 3 and 4). Also, CloudSat radar-only LWP is on average higher than ship observations and passive microwave satellite measurements over this region (e.g., Figs. 1 and 3). These differences in cloud thickness result in a very different relationship between LWP and $h$ from CloudSat/CALIPSO $\left(\mathrm{LWP} \sim h^{9}\right)$ as opposed to that from in situ observations (LWP $\sim h^{2}$, Fig. 2a).

The overestimates in radar-derived LWP are to be expected due to increased sensitivity to precipitation. Such effects are reduced in LWP closer to the coast (at $75^{\circ} \mathrm{W}$ vs. at $85^{\circ} \mathrm{W}$, i.e., Fig. 4 e vs. 4 a) where precipitation occurrence is reduced (Leon et al., 2008, Fig. 4a). Such effects would also be reduced by eliminating probable precipitating profiles. The current CloudSat flag based on a threshold of the near-surface reflectivity $Z_{s} \geq-15 \mathrm{dBZ}$ only removes $4 \%$ of the good-quality profiles in October-December 2008. A threshold based on the maximum reflectivity $\left(Z_{\max }\right)$ eliminates more profiles, decreases the bias relative to AMSR-E and SSM/I, and decreases the standard deviation of the differences relative to the LWPs from these two passive microwave products as the threshold is lowered and as the maximum height that the threshold is applied is increased. The lowest in magnitude mean differences occur for $Z_{\max }>-15 \mathrm{dBZ}$ searched for in the apparent lower half of the cloud (Table 2). When suspected profiles contaminated by precipitation are removed using this threshold, most CloudSat LWPs compare well with ship observations (e.g., Figs. 3a, 4a).

There are two factors that make the determination of cloud base in the CloudSat team product 2B-GEOPROF-LIDAR problematic. Sometimes, the lidar beam is fully attenuated in low-level clouds like those prevalent in this region. When a cloud base is unable to be determined by the lidar, the value based on the CPR is used which is highly affected by precipitation. Lidar determination of cloud base can also be a bit tenuous in the presence of precipitation (Winker and Vaughan, 1994). Thus, CloudSat/CALIPSO cloud bases should not be used. Instead, cloud base can be determined from the cloud thicknesses calculated using Eq. (1) from only those LWPs that are likely precipitation-free as determined above. Such adiabatic cloud bases are improved compared to the ship observations (e.g., Fig. 3c, 4c).

The ship and satellite measurements both show a clear diurnal cycle at $\left(20^{\circ} \mathrm{S}, 85^{\circ} \mathrm{W}\right)$ with maximum LWP and cloud fraction at night and minimum in these quantities during the day (Fig. 4a, b). A similar diurnal cycle exists in the ship and satellite measurements at the SHOA buoy site $\left(20^{\circ} \mathrm{S}, 75^{\circ} \mathrm{W}\right)$ closer to the coast (Fig. 4e, f) with a secondary maximum in the evening possibly associated with the passage of the upsidence wave (Rahn and Garreaud, 2010).

An important motivation of these data analyses is the use of these data for model evaluation. We have used these data to preliminarily evaluate the performance of the Community Atmosphere Model (CAM3.1). Figure 2a shows that CAM3.1 has LWPs that are nearly independent of $h$. Since model LWP is comparable to the ship observations (Fig. 5a, d), this is likely due to the simulated cloud being too thick and too low (Fig. 5b, c, e, f). However, the model is able to 
produce a logarithmic relationship between LWP and cloud fraction similar to that of the ship observations that does not appear in the satellite data (Fig. 2b). Additionally, CAM3.1 is able to correctly capture the diurnal cycle at $\left(20^{\circ} \mathrm{S}, 85^{\circ} \mathrm{W}\right)$ but has an opposite diurnal cycle at $\left(20^{\circ} \mathrm{S}, 75^{\circ} \mathrm{W}\right)$ (Fig. 6). Such discrepancies have also been seen in other models (e.g., Duynkerke and Teixeira, 2001; Siebesma et al., 2004).

In the newest version of the model (CAM4), there is some improvement in the diurnal cycle at $\left(20^{\circ} \mathrm{S}, 75^{\circ} \mathrm{W}\right)$ (Fig. 6eh) as well as in cloud top overall (e.g., Fig. 5d, h). Even so, simulated clouds are still too thick and too low, as the model cloud bases are almost always down to or near the surface (e.g., Fig. 5c, g). Cloud fraction is degraded further also (e.g., Fig. 5b, f).

Furthermore, these analyses provide a context for the interpretation of the work in the other papers in this Variability of the American Monsoon Systems Ocean Cloud Atmosphere Land Study (VOCALS) special issue. It is recognized that both the satellite datasets and the model are continually being updated, so future work will include data from the recent VOCALS Regional Experiment conducted in October-November 2008 to analyze any updated versions of the CloudSat collocated data. Future work will also explore the reasons for the differences between the two versions of CAM.

Acknowledgements. This study was supported by NSF grants (ATM-0745661 and ATM-0934275) and a NOAA grant (NA060AR4310056). J. Teixeira, A. A. Kokhanovsky, and Z. Wang along with two anonymous reviewers are thanked for their helpful comments. We also sincerely appreciate the numerous groups involved in the development of the various satellite and ship- and aircraft-based datasets used in this study and to NSF and NCAR for providing the computing facility to run CAM4.

Edited by:

\section{References}

Albrecht, B. A., Fairall, C. W., Thomson, D. W., White, A. B., Snider, J. B., and Schubert, W. H.: Surface-based remote sensing of the observed and the adiabatic liquid water content of stratocumulus clouds, Geophys. Res. Lett., 17, 89-92, 1990.

Austin, P., Wang, Y., Pincus, R., and Kujula, V.: Precipitation in stratocumulus clouds: Observational and modeling results, J. Atmos. Sci., 52, 2329-2352, 1995.

Bony, S., Colman, R., Kattsov, V. M., et al.: How well do we understand and evaluate climate change feedback processes?, J. Climate, 19, 3445-3482, 2006.

Bretherton, C. S., Uttal, T., Fairall, C., Yuter, S. E., Weller, R. A., Baumgardner, D., Comstock, K., Wood, R., and Raga, G. B.: The EPIC 2001 stratocumulus study, Bull. Amer. Meteor. Soc., 85, 967-977, 2004.

Comstock, K. K., Wood, R., Yuter, S. E., and Bretherton, C. S.: Reflectivity and rain rate in and below drizzling stratocumulus, Q. J. Roy. Meteorol. Soc., 130, 2891-2918, 2004. de Szoeke, S. P., Fairall, C. W., and Pezoa, S.: Ship observations of the tropical Pacific Ocean along the coast of South America, J. Climate, 22, 458-464, 2009.

de Szoeke, S. P., Fairall, C. W., Wolfe, D. E., Bariteau, L., Zuidema, P.: Surface flux observations on the southeastern tropical $\mathrm{Pa}-$ cific Ocean and attribution of SST errors in coupled oceanatmopshere models, J. Climate, in press, 2010.

Duynkerke, P. G. and Teixeira, J.: Comparison of the ECMWF reanalysis with FIRE I observations: Diurnal variation of marine stratocumulus, J. Climate, 14, 1466-1478, 2001.

Haynes, J. M., L'Ecuyer, T. S., Stephens, G. L., Miller, S. D., Mitrescu, C., Wood, N. B., and Tanelli, S.: Rainfall retrieval over the ocean with spaceborne W-band radar, J. Geophys. Res., 114, D00A22, doi:10.1029/2008JD009973, 2009.

Klein, S. A. and Hartmann, D. L.: The seasonal cycle of low stratiform clouds, J. Climate, 6, 1587-1606, 1993.

Kollias, P., Fairall, C. W., Zuidema, P., Tomlinson, J., and Wick, G. A.: Observations of marine stratocumulus in SE Pacific during the PACS 2003 cruise, Geophys. Res. Lett., 31, L22110, doi:10.1029/2004GL020751, 2004.

Leon, D. C., Wang, Z., and Liu, D.: Climatology of drizzle in marine boundary layer clouds based on 1 year of data from CloudSat and Cloud-Aerosol Lidar and Infrared Pathfinder Satellite Observations (CALIPSO), J. Geophys. Res., 113. D00A14, doi:10.1029/2008JD009835, 2008.

Li, J.-L. F., Waliser, D., Woods, C., Teixeira, J., Bacmeister, J., Chem, J., Shen, B.-W., Tompkins, A., Tao, W.-K., and Köhler, M.: Comparisons of satellites liquid water estimates to ECMWF and GMAO analyses, 20th century IPCC AR4 climate simulations, and GCM simulations, Geophys. Res. Lett., 35, L19710, doi:10.1029/2008GL035427, 2008.

Ma, C.-C., Mechoso, C. R., Robertson, A. W., and Arakawa, A.: Peruvian stratus clouds and the tropical Pacific circulation: A coupled ocean-atmosphere GCM study, J. Climate, 9, 1635-1645, 1996.

Matrosov, S. Y., Uttal, T., and Hazen, D. A.: Evaluation of radar reflectivity-based estimates of water content in stratiform marine clouds, J. Appl. Meteor., 43, 405-419, 2004.

O’Dell, C. W., Wentz, F. J., and Bennartz, R.: Cloud liquid water path from satellite-based passive microwave observations: A new climatology over the global oceans, J. Climate, 21, 1721-1739, 2008.

Pawlowska, H., Brenguier, J. L., and Burnet, F.: Microphysical properties of stratocumulus clouds, Atmos. Res., 55, 15-33, 2000.

Rahn, D. A. and Garreaud, R.: Marine boundary layer over the subtropical southeast Pacific during VOCALS-REx - Part 1: Mean structure and diurnal cycle, Atmos. Chem. Phys., 4491-4506, doi:10.5194/acp-10-4491-2010, 2010.

Räisänen, P., Isaac, G. A., Barker, H. W., and Gultepe, I.: Solar radiative transfer for stratiform clouds with horizontal variations in liquid-water path and droplet effective radius, Q. J. R. Meteorol. Soc., 129, 2135-2149, 2003.

Reynolds, R. W., Rayner, N. A., Smith, T. M., Stokes, D. C., and Wang, W.: An improved in situ and satellite SST analysis for climate, J. Climate, 15, 1609-1625, 2002.

Serpetzoglou, E., Albrecht, B. A., Kollias, P., and Fairall, C. W.: Boundary layer, cloud, and drizzle variability in the southeast Pacific stratocumulus regime, J. Climate, 21, 6191-6214, 2008. 
Siebesma, A. P., Jakob, C., Lenderink, G., Neggers, R. A. J., Teixeira, J., Van Meijgaard, E., Calvo, J., Chlond, A., Grenier, H., Jones, C., Köhler, M., Kitagawa, H., Marquet, P., Lock, A. P., Müller, F., Olmeda, D., and Severijns, C.: Cloud representation in general-circulation models over the northern Pacific Ocean: A EUROCS intercomparison study, Q. J. Roy. Meteorol. Soc., 130, 324-3267, 2004.

Stephens, G. L., Vane, D. G., Tanelli, S., Im, E., Durden, S., Rokey, M., Reinke, D., Partain, P., Mace, G. G., Austin, R., L'Ecuyer, T., Haynes, J., Lebsock, M., Suzuki, K., Waliser, D., Wu, D., Kay, J., Gettelman, A., Wang, Z., and Marchand, R.: CloudSat mission: Performance and early science after the first year of operation, J. Geophys. Res., 113, D00A18, doi:10.1029/2008JD009982, 2008.

Wang, J. and Geerts, B.: Identifying drizzle within marine stratus with W-band radar reflectivity, Atmos. Res., 69, 1-27, 2003.

Wentz, F. J.: A well-calibrated ocean algorithm for special sensor microwave/imager, J. Geophys. Res., 102, 8703-8718, 1997.

White, A. B., Fairall, C. W., and Snider, J. B.: Surface-based remote sensing of marine boundary-layer cloud properties, J. Atmos. Sci., 52, 2827-2838, 1995.
Winker, D. M. and Vaughan, M. A.: Vertical distribution of clouds over Hampton, Virginia observed by lidar under the ECLIPS and FIRE ETO programs, Atmos. Res., 34, 117-133, 1994.

Winker, D. M., Hunt, W. H., and McGill, M. J.: Initial performance assessment of CALIOP, Geophys. Res. Lett., 34, L19803, doi:10.1029/2007GL030135, 2007.

Wood, R. and Field, P. R.: Relationships between total water, condensed water, and cloud fraction in stratiform clouds examined using aircraft data, J. Atmos. Sci., 57, 1888-1905, 2000.

Zhou, M., Zeng, X., Brunke, M., Zhang, Z., and Fairall, C.: An analysis of statistical characteristics of stratus and stratocumulus over eastern Pacific, Geophys. Res. Lett., 33, L02807, doi:10.1029/2005GL024796, 2006.

Zuidema, P. and Hartmann, D. L.: Satellite determination of stratus cloud microphysical properties, J. Climate, 8, 1638-1657, 1995.

Zuidema, P., Westwater, E. R., Fairall, C., and Hazen, D.: Shipbased liquid water path estimates in marine stratocumulus. J. Geophys. Res., 110, D20206, doi:10.1029/2005JD005833, 2005. 